\title{
Smoking and sugar intake are separate but interactive risk factors in Crohn's disease
}

\author{
B KATSCHINSKI, R F A LOGAN, M EDMOND, AND M J S LANGMAN \\ From the Departments of Therapeutics and Community Medicine and Epidemiology, University of \\ Nottingham, Nottingham
}

Summary Previous studies have consistently found strong positive associations between refined sugar intake and Crohn's disease (CD) and recently between smoking and CD. As refined sugar intake and smoking are themselves associated we have enquired about smoking and added sugar intake (AS) and smoking in CD using a postal questionnaire sent to $104 \mathrm{CD}$ patients and 153 community controls. Smoking and AS were associated with one another. After adjusting for AS, smoking showed a significant association with $C D$ with a relative risk of $1 \cdot 8$. After adjusting for smoking habit, AS was also strongly associated with $\mathrm{CD}$ in never and exsmokers and in a dose response pattern, with the relative risks for no $\mathrm{AS},<50 \mathrm{~g} /$ day and $>50 \mathrm{~g} /$ day being respectively $1 \cdot 0$, $1 \cdot 8$, and $4.6\left(\chi^{2}=12 \cdot 1 ; p<0 \cdot 005\right)$. No association between CD and AS was evident in smokers. The AS relationship was supported by a separate association between frequency of confectionery consumption and $C D$. These findings indicate that while smoking and $A S$ are individually associated with CD combined exposure results in no further increase in risk, suggesting that they may operate through a common mechanism.

Increased refined sugar consumption by patients with Crohn's disease (CD) was first reported by Martini and Brandes in 1976 and has since been demonstrated in many studies, although some have suggested that the increased consumption is secondary to the development of $\mathrm{CD} .^{1-4} \mathrm{We}$, and subsequently others, have recently found a strong association between smoking and $\mathrm{CD}$ which antedates disease onset. ${ }^{12-1.5}$ Smoking has previously been found to be positively associated with sugar consumption. ${ }^{16}{ }^{17}$ It therefore seemed possible that the association of smoking or sugar consumption with CD might be due to confounding, that is, any increase in smoking, or sugar consumption, in $\mathrm{CD}$ patients might be accounted for by the one habit being associated with the other. We have therefore reapproached subjects from our earlier study with a second questionnaire designed to determine whether the association of smoking and $C D$ was related to increased sugar consumption by smokers with $\mathrm{CD}$.

Address for correspondence: Dr R F A Logan, Dept of Community Medicine and Epidemiology. University of Nottingham. Queens' Medical Centre, Nottingham, NG7 2UH.

Received for publication 7 April 1988.

\section{Methods}

\section{PATIENTS}

This was a case control study using cases and controls who had been first approached two to four years earlier for a study of smoking and Crohn's disease. ${ }^{101} 18$ The original case series had consisted of 142 patients representing all patients with $C D$ aged $16-80$ years from a defined group of 52 general practices who were also attending or had previously attended either the City or University Hospitals, Nottingham. Each patient had been matched with two controls who had been chosen by visiting the patient's general practice and using the practice records or age and sex register to select the next two people listed alphabetically of the same sex and age within two years. Of the original 142 cases and 284 matched controls 129 cases and 212 controls had returned the first questionnaire and were therefore approached with a second postal questionnaire a minimum of two years later.

The one page questionnaire consisted of six questions asking about current intake of sugar added to tea, coffee, and breakfast cereals and about confectionery consumption, any change in added 
sugar habit and current smoking habit. If the questionnaire had not been returned after six to eight weeks, a second letter and questionnaire was sent. Added sugar consumption (AS) refers to sugar added to tea or coffee which usually constitutes about half of total refined sugar consumption. ${ }^{16}{ }^{19}$ For the purposes of analysis smoking was defined arbitrarily as smoking more than five cigarettes weekly and one teaspoonful of sugar was estimated to weigh $5 \mathrm{~g}$.

Results were analysed using conventional methods with the relative risk estimates (RR) being the odds ratios obtained using the Mantel-Haenszel approach. ${ }^{20}$

\section{Results}

After excluding patients and controls who had died or were known diabetics and questionnaires returned as address incorrect, changed or addressee unknown the response rate from $\mathrm{CD}$ patients and controls was similar with $85 \%(n=104)$ of patients and $84 \%$ $(n=153)$ of controls returning the questionnaire. Case and control series were of similar age and sex distribution with $34 \%$ of $\mathrm{CD}$ patients responding being men compared with $35 \%$ of the controls. The proportions aged $<20,20-39,40-59$ and $>60$ years were $5 \%, 52 \%, 30 \%$, and $13 \%$ of the CD patients responding and $5 \%, 54 \%, 32 \%$, and $9 \%$ of the controls responding.

Table 1 Added sugar-daily intake reported

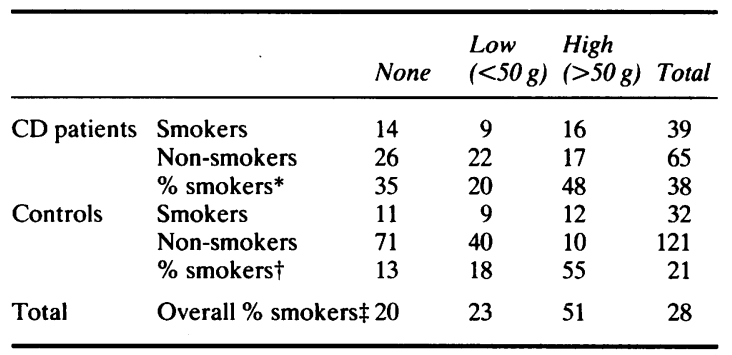

${ }^{*} \chi^{2}=2 \cdot 7 ; p>0.05 ; \nmid \chi^{2}=17.9 ; p<0.001 ; \ddagger \chi^{2}=14.4 ; p<0.001$.

Table 2 Added sugar-daily intake reported

\begin{tabular}{|c|c|c|c|c|}
\hline & & None & $\begin{array}{l}\text { Low } \\
(<50 \mathrm{~g})\end{array}$ & $\begin{array}{l}\text { High } \\
(>50 \mathrm{~g})\end{array}$ \\
\hline \multirow{3}{*}{$\begin{array}{l}\text { Non- } \\
\text { smokers }\end{array}$} & CD patients & 26 & 22 & 17 \\
\hline & RR & $1.0 \dagger$ & $1 \cdot 5$ & $4 \cdot 6$ \\
\hline & Controls & 71 & 40 & 10 \\
\hline \multirow[t]{4}{*}{ Smokers } & CD patients & 14 & 9 & 16 \\
\hline & $\mathbf{R R}$ & $3 \cdot 5$ & $2 \cdot 7$ & 3.6 \\
\hline & Controls & 11 & 9 & 12 \\
\hline & $\begin{array}{l}\text { Adjusted RR } \\
\text { 95\% confidence limits }\end{array}$ & $1.0^{*}$ & $\begin{array}{l}1 \cdot 3^{*} \\
0 \cdot 7-2 \cdot 3\end{array}$ & $\begin{array}{l}2 \cdot 5^{*} \\
1 \cdot 3-4 \cdot 8\end{array}$ \\
\hline
\end{tabular}

${ }^{*} \chi^{2}=7 \cdot 7 ; p<0.025 ;$ treferent level.
ARE SMOKING AND AS ASSOCIATED?

Table 1 shows that there was an association between smoking and increased AS in the whole study group with $51 \%$ of high AS takers reporting being smokers, compared with $20 \%$ of no AS takers being smokers. Although the association was more evident in the controls, a similar but weaker trend was present in CD patients.

IS AS ASSOCIATED WITH CD IN SMOKERS AND NON-SMOKERS?

Table 2 examines whether the association between $\mathrm{CD}$ and AS was caused by confounding by smoking. Patients and controls who were non-smokers and took no added sugar have been designated as the referent group. In non-smokers the relative risk of having $C D$ was found to increase with increasing AS $\left(\chi^{2}=12.1 ; p<0.005\right)$ whereas in smokers the risk showed no association with added sugar intake $\left(\chi^{2}=\right.$ $0 \cdot 24)$. After adjustment for differences in the number of cases and controls who smoked a significant association was still evident overall between AS and $\mathrm{CD}\left(\chi^{2}=7 \cdot 7, \mathrm{p}<0.025\right)$.

IS SMOKING ASSOCIATED WITH CD AFTER ADJUSTING FOR AS?

Table 2 shows that an increased risk of $C D$ was present in smokers compared with non-smokers, who took no added sugar, the relative risk being 3.5 (95\% confidence limits $1.4-8.4)$ compared with the referent level of $1 \cdot 0$. By contrast in individuals taking $>50 \mathrm{~g} /$ day of added sugar there was no increase in smokers, the relative risks being 3.6 and 4.6 in smokers and non-smokers giving a comparative risk of $0 \cdot 8$ for smokers $(95 \%$ confidence limits $0 \cdot 3-2 \cdot 3)$. In the intermediate group of takers of $<50 \mathrm{~g}$ of sugar daily the relative risks were respectively 2.7 and 1.5 in smokers and non-smokers, giving a comparative value of $1 \cdot 8(95 \%$ confidence limits $0 \cdot 7-2 \cdot 8)$.

After adjustment for differences in added sugar intake in the whole subject group there remained a significant association of smoking with Crohn's disease with a relative risk of 1.8 (95\% confidence limits 1·04-3.2).

Table 3 Added sugar-daily intake \% reporting

\begin{tabular}{llllll}
\hline & & & 40 & 80 & \\
& None & $<40 g$ & $79 g$ & $119 g$ & $>120 g$ \\
\hline CD patients $(\mathrm{n}=104)$ & 38 & 26 & 22 & 12 & 2 \\
Controls (n=153) & 53 & 24 & 14 & 5 & 4 \\
& RR* 1.0 & 1.5 & $2 \cdot 3$ & 3.5 & 0.7 \\
$95 \%$ confidence upper - & 2.8 & 4.5 & 9.2 & 3.5 \\
limits & lower - & 0.8 & 1.1 & 1.3 & 0.1 \\
\hline
\end{tabular}

*Overall $\chi^{2}=10 \cdot 4 ; p<0.05 ; \chi^{2}$ for trend $=4.76 ; p<0.05$ 
Table 4 Responses to other questions

\begin{tabular}{|c|c|c|c|c|c|}
\hline Question & $\begin{array}{l}\text { CD patients } \\
(n=104)\end{array}$ & $\begin{array}{l}\text { Controls } \\
(n=153)\end{array}$ & $\chi^{2}$ & $p$ & $R R$ \\
\hline Do you drink coffee regularly? & $63 \%$ & $72 \%$ & $2 \cdot 1$ & $0 \cdot 15$ & - \\
\hline Do you drink tea regularly? & $84 \%$ & $84 \%$ & () & $1 \cdot()$ & - \\
\hline Sugar added to tea or coffee & $62 \%$ & $46 \%$ & $5 \cdot 1$ & $0 \cdot() 25$ & - \\
\hline $\begin{array}{l}\text { Do you add sugar to other foods } \\
\text { or drinks? }\end{array}$ & $54 \%$ & $41 \%$ & 3.7 & $0 \cdot 0.54$ & - \\
\hline Never or $<$ monthly & $8 \%$ & $14 \%$ & & & $1 \cdot()^{*}$ \\
\hline Monthly or weekly & $56 \%$ & $64 \%$ & $6 \cdot 8$ & $0 \cdot() 4$ & $1 \cdot 7$ \\
\hline More than 3 times a week & $36 \%$ & $22 \%$ & & & $3 \cdot(0)$ \\
\hline \multicolumn{6}{|l|}{$\begin{array}{l}\text { In the past } 10 \text { years has the } \\
\text { amount of sugar you add ...? }\end{array}$} \\
\hline Increased & $7 \%$ & $1 \%$ & & & - \\
\hline Decreased & $41 \%$ & $48 \%$ & $5 \cdot 8$ & 0.056 & - \\
\hline Not changed & $52 \%$ & $51 \%$ & & & \\
\hline
\end{tabular}

${ }^{*}$ Referent level; $\dagger \chi^{2}$ test for trend $=6 \cdot 2, p<0 \cdot() 2$.

OTHER ASPECTS OF AS IN CD

When AS is further divided into $40 \mathrm{~g}$ daily increments a significant relationship between increasing AS and having $C D$ can also be shown (Table 3 ). A relationship between $C D$ and sugar intake was further supported by the other responses to the questionnaire as shown in Table 4. A greater proportion of CD patients reported adding any sugar to tea and coffee and to other foods and drinks. Crohn's disease patients were also more likely to report high levels of confectionery consumption.

RECENT CHANGES IN SMOKING AND AS

Table 5 analyses how the relationships between smoking, AS and CD were affected by changes in smoking habit since onset of CD. Patients who according to our first study were smokers at onset of $\mathrm{CD}$ and have continued to report being smokers have been classified as 'continuing smokers'. For those reporting having never smoked $(n=137)$, a strong relationship between $\mathrm{AS}$ and $\mathrm{CD}$ was evident with those taking high AS having five times the risk of CD compared with those taking no AS $\left(\chi^{2}=8 \cdot 4\right.$, $\mathrm{p}<0.025)$. A similar relationship was evident for exsmokers but only 45 patients and controls were

Table 5 Added sugar-daily intake reported

\begin{tabular}{|c|c|c|c|c|}
\hline & & None' & $\begin{array}{l}\text { Low } \\
(<50 \mathrm{~g})\end{array}$ & $\begin{array}{l}\text { High } \\
(>50 \mathrm{~g})\end{array}$ \\
\hline \multirow{4}{*}{$\begin{array}{l}\text { Never smoked } \\
\text { Exsmokers } \\
\text { Continuing smokers } \dagger\end{array}$} & & $1 \cdot 0)^{*}$ & $1 \cdot 6$ & $5 \cdot 1$ \\
\hline & & $2 \cdot 9$ & $6 \cdot 6$ & $11 \cdot 8$ \\
\hline & & $6 \cdot 4$ & $4 \cdot 4$ & $5 \cdot 9$ \\
\hline & $\begin{array}{l}\text { adj. RR } \\
(95 \% \mathrm{cl})\end{array}$ & $1 \cdot 0$ & $\begin{array}{l}1 \cdot 4 \\
0 \cdot 76-2 \cdot 6\end{array}$ & $\begin{array}{l}2 \cdot 4 \\
1 \cdot 2-4 \cdot 8\end{array}$ \\
\hline
\end{tabular}

*Referent value. Table shows RR's only; †smoked at disease onset and continued to smoke. exsmokers and the relationship was statistically weak $\left(\chi^{2}=2 \cdot 84, p>0 \cdot 1\right)$. As with the analyses based on current smoking habit (Table 2) no association between AS and CD was present in "continuing smokers'.

As a further check on whether recent changes in reported smoking affected the results, current AS was also analysed in terms of smoking habit reported on the first questionnaire. According to previously reported smoking habit and taking no AS as the referent level the adjusted RR of having CD was 1.4 $(95 \% \mathrm{cl} 0 \cdot 7-2 \cdot 6)$ for low AS and $2 \cdot 6(95 \% \mathrm{cl} 1 \cdot 3-5 \cdot 1)$ for high $\operatorname{AS}\left(\chi^{2}=7 \cdot 2, \mathrm{p}<0 \cdot 05\right)$.

\section{Discussion}

Smoking and increased refined sugar consumption are the only environmental factors that have been associated with $C D$ with any consistency. ${ }^{1-15}$ The purpose of this study was to determine whether the confounding effect of smoking on refined sugar consumption found in studies of ischaemic heart disease might also account for the association of one or other habit with $\mathrm{CD}$.

To measure refined sugar intake we used a very simple quantity of sugar added questionnaire as this approach has been frequently used previously and found to be as capable of detecting a relationship between $C D$ and refined sugar intake as longer questionnaires. A short questionnaire was felt to be important in ensuring the continued cooperation and response to a postal enquiry by people who had already helped us some years earlier. Although the questionnaire enquired only about added sugar intake, about a half of total refined sugar intake consists of sugar taken in this way and there is a good correlation between the two measures. ${ }^{19}$ 
Ideally a new series of recently diagnosed $\mathrm{CD}$ patients and controls would have been used to reduce the likelihood of any bias resulting from making a second approach to prevalent cases. The numbers of new cases available was not sufficient, however, and it is difficult to conceive how the results obtained might be accounted for by bias or changes secondary to developing CD. As some patients already know of the linking of $C D$ with refined sugar intake they might be expected to have, if anything, reduced their refined sugar intake in the hope of ameliorating their condition. It seems likely also that patients regularly attending hospital would have a greater tendency to stop smoking. Either of these biases, if present, would reduce the differences found between $C D$ patients and controls and thus have a conservative effect. Such an effect probably explains why the relationship between current smoking and CD (RR $1 \cdot 8,95 \%$ confidence limits $1 \cdot 04-3 \cdot 2$ ) was weaker than that found when patients and controls were first approached (RR 3.1, 95\% confidence limits 2.0$4 \cdot 9){ }^{18}$

The estimates of added sugar intake that we have obtained are similar to those of previous studies with smokers taking about a third more added sugar than non-smokers. Watching smokers taking tea or coffee will usually dispel any doubts as to the reality of this phenomenon! Our results show a consistent association between $\mathrm{CD}$ and added sugar intake and other measures of sugar consumption such as confectionery consumption and use of sugar added to other foods and drinks. It has been suggested that the increased sugar intake may be secondary to the development of CD. In support of this Jarnerot et al found no association between refined sugar intake and CD in patients interviewed within six months of diagnosis compared to patients interviewed a longer time after diagnosis." As our study involved only prevalent CD patients it was not possible to examine this question. Nevertheless considering the difficulties experienced in demonstrating consistent dietary relationships for other diseases it is remarkable that the association of $\mathrm{CD}$ and refined sugar intake has been shown so frequently and consistently and often with simple questionnaires and crude statistical methods."

Of the possible inter-relationships between smoking and sugar intake and CD that might be hypothesised the one suggested by these results is arguably the most intriguing. When classified by current habit (Table 2 ) by previous and current habit (Table 5) or by previous habit alone the relative risk of having $\mathrm{CD}$ in smokers was unrelated to added sugar intake whereas in non-smokers or in never and exsmokers the RR of having $C D$ increased with increases in added sugar intake. The pathophysiological mechanisms through which smoking or refined sugar could exert aetiological effects are unknown. The data presented suggest that both could operate or trigger a common mechanism as the combination of both factors results in neither an additive nor a multiplicative increase in risk of $C D$.

Presented at the British Society of Gastroenterology Jubilee Meeting London, September 1987.

\section{References}

1 Martini GA, Brandes JN. Increased consumption of refined carbohydrates in patients with Crohn's Disease. Klin Wochenschr 1976; 54: 367-71.

2 Kaspar H, Sommer H. Dietary fibre and nutrient intake in Crohn's disease. Am J Clin Nutr 1979; 32: 898-9()1.

3 Thornton JR, Emmett PM, Heaton KW. Diet and Crohn's disease: characteristics of the pre-illness diet. Br Med J 1979; ii: 762-4.

4 Mayberry JF, Rhodes J, Newcombe RG. Increased sugar consumption in Crohn's discase. Digestion 1980; 20: $323-6$.

5 Jarnerot G, Jarnmark I, Nilsson K. Consumption of refined sugar by patients with Crohn's disease. Scand J Gastroenterol 1983; 18: 999-1002.

6 Silkoff K, Hallak A, Yegena L, et al. Consumption of refined carbohydrate by patients with Crohn's disease in Tel-Aviv-Yafo. Postgrad Med J 1980; 56: 842-6.

7 Mayberry JF, Rhodes J, Allan R, et al. Diet in Crohn's disease - Two studies of current and previous habits in newly diagnosed patients. Dig Dis Sci 1981; 26: 444-8.

8 Panza E, Franceschi S, La Vecchia C, et al. Dietary factors in the actiology of inflammatory bowel discase. Ital J Gastroenterol 1987; 19: 205-9.

9 Persson PG, Ahlbom A, Hellers G. Crohn's disease and ulcerative colitis - a review of dietary studies with emphasis on methodologic aspects. Scand J Gastroenterol 1987; 22: 385-9.

10 Somerville KW, Logan RFA, Edmond M, Langman MJS. Smoking and Crohn's disease. Br Med J 1984; 289: 954-6.

11 Vessey M, Jewell D, Smith A. Yeates D, McPherson K. Chronic inflammatory bowel disease, cigarette smoking, and use of oral contraceptives: findings in a large cohort study of women of childbearing age. Br Med J 1986; 292: 1101-3.

12 Francheschi S, Panza E, Vecchia C, Parazzini D, Decarli A, Bianchi Porro G. Non-specific inflammatory bowel disease and smoking. Am J Epidemiol 1987; 125: 445-52.

13 Tobin MV, Logan RFA, Langman MJS, McConnell RB, Gilmore IT. Cigarette smoking and inflammatory bowel disease. Gastroenterology 1987; 93: 316-21.

14 Lindberg E, Tysk C, Jarnerot G, Andersson K. Smoking and inflammatory bowel disease. Scand $J$ Gastroenterol 1986; 21: [suppl 120]: 4.

15 Calkins B, Lilienfield A, Mendelhoff A, et al. Smoking factors in ulcerative colitis and Crohn's disease in Baltimore. Am J Epidemiol 1984; 120: 498.

16 Bennett AE, Doll R, Howell RW. Sugar consumption and cigarette smoking. Lancet 1970; i: 1011-4. 
17 Elwood PC, Waters WE, Moore S, Sweetnam P. Sucrose consumption and ischaemic heart disease in the community. Lancet 1970; i: 1014-6.

18 Logan RFA, Katschinski B, Somerville KW, Pearson JCG, Langman MJS. Smoking and inflammatory bowel disease. Gastroenterology 1986; 90: 1525.
19 Yudkin J, Roddy J. Assessment of sugar intake: validity of the questionnaire method. Br J Nutr 1966; 20: 80711.

20 Breslow NE, Day NE. Statistical methods in cancer research. Vol 1. The analysis of case-control studies. Lyon: IARC, 1980. 